\title{
Targeting LRH-1 in hepatoblastoma cell lines causes decreased proliferation
}

\author{
JINGLING JIN ${ }^{1,2 *}$, JUNLIANG JIN ${ }^{3 *}$, SARAH E. WOODFIELD ${ }^{1 *}$, ROMA H. PATEL ${ }^{1 *}$, \\ NAN GE JIN ${ }^{4 *}$, YAN SHI ${ }^{1}$, BIN LIU ${ }^{2}$, WENJING SUN ${ }^{1}$, XIANGMEI CHEN ${ }^{5}$, \\ ${\text { YANG } \mathrm{YU}^{1} \text { and SANJEEV A. VASUDEVAN }}^{1}$
}

\author{
${ }^{1}$ Divisions of Pediatric Surgery and Surgical Research, Michael E. DeBakey, Department of Surgery; \\ ${ }^{2}$ Department of Pediatrics-Oncology, Baylor College of Medicine, Texas Children's Hospital, Houston, \\ TX 77030; ${ }^{3}$ Carnegie Vanguard High School, Houston, TX 77019; ${ }^{4}$ Ruiz Department of Ophthalmology \\ and Visual Science, University of Texas Health Science Center at Houston, Houston, TX 77030, USA; \\ ${ }^{5}$ Department of Microbiology \& Infectious Disease Center, School of Basic Medical Science, \\ Peking University Health Science Center, Beijing 100191, P.R. China
}

Received March 26, 2018; Accepted September 7, 2018

DOI: $10.3892 / o r .2018 .6793$

\begin{abstract}
Hepatoblastoma is the most common malignant liver tumor in children. Since it is often unresectable and exhibits drug resistance, the treatment of advanced hepatoblastoma is challenging. The orphan nuclear receptor liver receptor homolog-1 (LRH-1) serves prominent roles in malignancy; however, to the best of our knowledge, the role of LRH-1 in hepatoblastoma remains unknown. In the present study, human hepatoblastoma cell lines were analyzed; the mRNA and protein expression levels of LRH-1 were significantly higher in HepG2 and HuH6 cells compared with those in HepT1 cells and control THLE-2 cells. Knockdown of LRH-1 resulted in decreased HepG2 and HuH6 cell proliferation via downregulation of cyclin D1 (CCND1) and c-Myc. Furthermore, treatment with an LRH-1 antagonist (LRA) inhibited the proliferation and colony formation of cell lines in a dose-dependent manner, and induced cell cycle arrest at $\mathrm{G}_{1}$ phase through inhibition of CCND1 expression. Finally, LRA treatment enhanced the cytotoxic effects of doxorubicin on hepatoblastoma cells.
\end{abstract}

Correspondence to: Dr Jingling Jin or Dr Sanjeev A. Vasudevan, Divisions of Pediatric Surgery and Surgical Research, Michael E. DeBakey, Department of Surgery, Baylor College of Medicine, Texas Children's Hospital, 1,102 Bates Avenue, Houston, TX 77030, USA

E-mail: jinglinj@bcm.edu

E-mail:sanjeevv@bcm.edu

${ }^{*}$ Contributed equally

Abbreviations: LRH-1, liver receptor homolog-1; dox, doxorubicin; CCK-8, Cell Counting Kit- 8 assay; IC $_{50}$, half maximal inhibitory concentration; PI, propidium iodide

Key words: LRH-1/NR5A2, hepatoblastoma, cell proliferation, CCND1, c-Myc
Collectively, these findings suggested that LRH-1 may have an important role in the progression of hepatoblastoma and implicated LRA as a novel, potential therapeutic agent for the treatment of hepatoblastoma.

\section{Introduction}

Hepatoblastoma is the most common malignant liver tumor in children $<5$ years old $(1,2)$. The prognosis of children with hepatoblastoma is favorable if a complete surgical resection of the tumor is possible; however, for advanced and unresectable tumors, and for relapsed cases, the prognosis is much worse $(2,3)$, and surgery combined with chemotherapy is required for long-term survival (1). The most commonly studied agents in the treatment of hepatoblastoma include cisplatin (4) and doxorubicin (dox) (5). Dox is commonly used in the treatment of a wide range of cancers, with the most serious adverse effect being life-threatening heart damage. Since multidrug resistance is a common problem encountered in response to chemotherapy for the treatment of hepatoblastoma $(6,7)$, the development of novel therapeutic strategies is critical.

The orphan nuclear receptor liver receptor homolog-1 [LRH-1, also known as nuclear receptor subfamily 5 group A member 2 (NR5A2)] is a member of a subfamily of nuclear receptors that binds to identical DNA consensus sequences (8). LRH-1 is primarily expressed in secretory tissues or tissues with high rates of protein production, such as the liver (9), pancreas $(10,11)$, breast (12) and muscle (13). LRH-1 has prominent roles in development, metabolism (8), stem cell pluripotency (14) and tumorigenesis, including in breast cancer (12), pancreatic cancer (15) and endometrial cancers (16). In the liver, LRH-1 regulates cholesterol metabolism and bile acid homeostasis (17). Transcriptional targets of LRH-1 include cyclin D1 (CCND1), cyclin E1 (CCNE1) and c-Myc, which are known to control cell differentiation, growth and proliferation (15). Inhibition of LRH-1 signaling has been successful in preclinical studies of some cancer 
types $(12,14,16)$; however, the role of LRH-1 in hepatoblastoma remains unclear. Development of small molecule agonists is a promising area of research $(17,18)$ and antagonists for LRH-1 may work as potent anticancer agents $(19,20)$. The present study assessed the antitumorigenic efficacy of the recently developed LRH-1 antagonist (LRA), pyrazolylbiphenylethanone compound 1-(3'-(1-(2-(4-Morpholinyl) ethyl)-1H-pyrazol-3-yl)-3-biphenylyl) ethanone, which can bind to the LRH-1 ligand binding domain and block LRH-1 from forming an active conformation (20).

In the present study, the expression levels of LRH-1 were examined in a panel of hepatoblastoma cell lines in vitro; the mRNA and protein expression levels were upregulated in HepG2 and Huh6 cells. Specific inhibition of LRH-1 using LRA inhibited proliferation of these cells through downregulation of CCND1 and c-Myc, and via induction of cell cycle arrest at $G_{1}$ phase. LRA also increased the antitumor effects of dox in these cells. Overall, the present study supports a role for LRH-1 in liver cancer and raises the possibility that inhibition of LRH-1 may be effective in the treatment of hepatoblastoma.

\section{Materials and methods}

Cell culture. The hepatoblastoma cell line HepG2 was grown in Eagle's Minimum Essential Medium (Lonza, Salisbury, MD, USA), HepT1 cells were grown in RPMI 1640 (Lonza), and HuH6 and 293T cells were grown in Dulbecco's modified Eagle's medium (DMEM; Lonza); all media were supplemented with $10 \%$ heat-inactivated fetal bovine serum (FBS, SAFC Biosciences, Inc., Lenexa, KS, USA), 2 mM L-glutamine (Thermo Fisher Scientific, Inc., Waltham, MA, USA) and $100 \mathrm{U} / \mathrm{ml}$ penicillin G/streptomycin (Thermo Fisher Scientific, Inc.). THLE-2 cells [American Type Culture Collection (ATCC), Manassas, VA, USA] were grown in Bronchial Epithelial Cell Growth Medium (Lonza) supplemented with $10 \% \mathrm{FBS}, 1 \%$ penicillin-streptomycin and $50 \mu \mathrm{g} \mathrm{ml}^{-1}$ gentamycin (Sigma-Aldrich; Merck KGaA, Darmstadt, Germany) in PureCol/fibronectin-coated T-75 flasks. HepG2, THLE-2 and 293T cells were purchased from ATCC; HuH6 cells were purchased from Riken BioResource Center (Tsukaba, Japan). HepT1 cells were a generous gift from Dr Stefano Cairo (Department of Morphology, Surgery and Experimental Medicine, University of Ferrara, Ferrara, Italy). All cells were incubated at $37^{\circ} \mathrm{C}$ in a humidified atmosphere containing $5 \%$ $\mathrm{CO}_{2}$ and $95 \% \mathrm{O}_{2}$.

Establishment of stable short hairpin (sh)RNA-mediated LRH-1 knockdown hepatoblastoma cell lines. shRNA-induced knockdown of LRH-1 expression was achieved using the lentiviral expression system from GE Healthcare Dharmacon, Inc. (Lafayette, CO, USA). The shLRH-1/shNR5A2 constructs used in the present study were as follows: \#1, V2LHS_17029; \#2, V2LHS_17033; \#3, RHS4 430-98486912 (GE Healthcare Dharmacon, Inc.). The shCCND1 construct used was RHS4531-EG595 (GE Healthcare Dharmacon, Inc.). The shc-Myc construct used was RHS4531-EG4609 GE Healthcare Dharmacon, Inc.). The control vector used was RHS4346 (GE Healthcare Dharmacon, Inc.). Viral particles were generated by co-transfecting 293 T cells (ATCC) with the shRNAs and the Lenti-vpak packaging kit, which contains packaging plasmids and a transfection reagent (cat. no. TR30037; OriGene Technologies, Inc., Rockville, MD, USA) according to the manufacturer's protocol. Subsequently, the shRNA viral particles were transduced into HepG2 and HuH6 cells with $8 \mu \mathrm{g} / \mathrm{ml}$ hexadimethrine bromide (Polybrene; cat. no. H9268; Sigma-Aldrich; Merck KGaA), and stable cell lines were established after 10 days of puromycin $(2 \mu \mathrm{g} / \mathrm{ml})$ selection. Knockdown was confirmed using quantitative polymerase chain reaction (qPCR) or immunoblotting. The selected cell lines were routinely cultured in puromycin-containing media until 2 days prior to experimentation.

$R N A$ extraction and reverse transcription $(R T)-q P C R$. The Direct-zol RNA miniprep kit (Zymo Research Corp., Irvine, CA, USA) was used to extract total RNA, according to the manufacturer's protocol. RT was conducted according to manufacturer's protocol, briefly, using random hexamer primers and the Transcriptor First Strand cDNA Synthesis kit (Roche Diagnostics, Indianapolis, IN, USA), and the resultant cDNA was subjected to qPCR analysis using TaqMan Universal PCR Master Mix (Applied Biosystems; Thermo Fisher Scientific, Inc.). Thermal cycling conditions were performed as follows: Pre-denaturation at $95^{\circ} \mathrm{C}$ for $5 \mathrm{~min}$, followed by 40 cycles of denaturation at $95^{\circ} \mathrm{C}$ for $10 \mathrm{sec}$, annealing at $60^{\circ} \mathrm{C}$ for $30 \mathrm{sec}$ and extension at $72^{\circ} \mathrm{C}$ for $30 \mathrm{sec}$ after which, a melting curve analysis was conducted. TaqMan assay mixtures targeting LRH-1/NR5A2 (Hs00187067_m1), GAPDH (Hs02758991), CCNE1 (Hs01026536_m1), CCND1 (Hs00765553_m1) and MYC (Hs00905030_m1) (Applied Biosystems; Thermo Fisher Scientific, Inc.) were used for the detection of mRNA expression. Amplification and quantification were performed using the PRISM 7000 Real-Time PCR system (Applied Biosystems; Thermo Fisher Scientific, Inc.). The mRNA expression levels of LRH-1, CCND1, CCNE1 and MYC were normalized to the mRNA levels of GAPDH, which was used as an internal control. The $2^{-\Delta \Delta \mathrm{Cq}}$ method (21) was used to quantify the mRNA expression levels. Data were analyzed by one-way analysis of variance and a Dunnett's multiple comparison post hoc test, or Student's t-test.

Antibodies and reagents. Antibodies against CCND1 (cat. no. sc-8396), CCNE1 (cat. no. sc-247), c-Myc (cat. no. sc-764) and LRH-1 (cat. no. sc-25389) were obtained from Santa Cruz Biotechnology, Inc. (Dallas, TX, USA). Anti-mouse (cat. no. 7076S) and anti-rabbit (cat. no. 7074S) immunoglobulin $\mathrm{G}$ secondary antibodies were obtained from Cell Signaling Technology, Inc. (Danvers, MA, USA). Anti-LRH-1/NR5A2 (cat. no. PA5-28347) was obtained from Thermo Fisher Scientific, Inc. Dox (cat. no. D1515) and anti- $\beta$-actin (cat. no. A2228) antibody were obtained from Sigma-Aldrich; Merck KGaA. LRA (cat. no. 505601) was purchased from Calbiochem; EMD Millipore (Billerica, MA, USA).

Protein isolation and western blotting. After each treatment, cells were harvested in ice-cold PBS (pH 7.4) and spun down. The pellets were dissolved in lysis buffer $[50 \mathrm{mM}$ Tris- $\mathrm{HCl}$, pH 7.4; 150 mM NaCl; 1 mM EDTA; 1\% IGEPAL; $0.25 \%$ Na-deoycholate; $1 \mathrm{mM}$ phenylmethyl-sulfonyl fluoride; $1 \mathrm{mM}$ dithiothreitol; $10 \mathrm{mg} / \mathrm{ml}$ aprotinin; $10 \mathrm{mg} / \mathrm{ml}$ leupeptin; $1 \mathrm{mM}$ 
benzamidine; $20 \mathrm{mM}$ disodium p-nitrophenylphosphate; $0.1 \mathrm{mM}$ sodium orthovanadate; $10 \mathrm{mM}$ sodium fluoride; phosphatase inhibitor cocktail A and B (Sigma-Aldrich; Merck KGaA)]. Proteins (50-100 $\mu \mathrm{g})$ were separated by $4-12 \%$ gradient SDS-PAGE (Invitrogen; Thermo Fisher Scientific, Inc.), transferred to nitrocellulose membranes using iBlot ${ }^{\mathrm{TM}} 2$ Transfer Stacks (Invitrogen; Thermo Fisher Scientific, Inc.) and were blocked overnight at $4^{\circ} \mathrm{C}$ in $5 \%$ milk/TBS- $0.1 \%$ Tween. The membranes were then probed with antibodies against proteins of interest. Membranes were incubated with primary antibodies at 1:1,000 dilution (vol/vol) overnight at $4{ }^{\circ} \mathrm{C}$, and with secondary antibodies at 1:5,000 dilution at room temperature for $1 \mathrm{~h}$. To verify protein loading, each sample was re-probed with $\beta$-actin. Western blots were visualized using the ECL-Plus Western blotting system (GE Healthcare Biosciences, Pittsburgh, PA, USA) or IRDye ${ }^{\circledR}$ Infrared Dye exposed on the Odyssey image system (Li-COR Biosciences, Lincoln, NE, USA). Blots were semi-quantified using ImageJ (Version 1.43; National Institutes of Health, Bethesda, MD, USA).

Cell viability assay. HepG2, HepT1 and HuH6 cells were plated in 96-well plates at a density of $2 \times 10^{4}$ cells/well. After they were allowed to settle for $24 \mathrm{~h}$, the cells were treated with increasing concentrations of LRA (0.1-100 $\mu \mathrm{M})$ for $72 \mathrm{~h}$. Cell viability was measured for consecutive days using the Cell Counting Kit-8 (CCK-8) assay (Dojindo Molecular Technologies Inc., Rockville, MD, USA), according to the manufacturer's protocol, by replacing the medium in each well with $10 \%$ CCK-8 solution $(10 \mu \mathrm{l} / 100 \mu \mathrm{l}) /$ media (v/v). After $2 \mathrm{~h}$ incubation at $37^{\circ} \mathrm{C}$, absorbance was measured at $450 \mathrm{~nm}$ using a standard plate reader (Beckman Coulter, Inc., Brea, CA, USA).

In experiments analyzing the combinatory effects of LRA with dox, the cells were seeded in 96-well plates and were treated with $10 \mu \mathrm{M}$ LRA combined with increasing concentrations of dox $(0-10 \mu \mathrm{M})$ for $48 \mathrm{~h}$ at $37^{\circ} \mathrm{C}$, after which, cell viability was measured using an MTT assay. Briefly, the medium in each well was replaced with $9 \%$ MTT $(5 \mathrm{mg} / \mathrm{ml}) / \mathrm{media}(\mathrm{v} / \mathrm{v})$. After $4 \mathrm{~h}$ incubation at $37^{\circ} \mathrm{C}, 85 \mu \mathrm{l}$ MTT/media was aspirated and $50 \mu \mathrm{l}$ dimethyl sulfoxide (DMSO) was added. The plate was then read at $550 \mathrm{~nm}$ using a multimode plate reader (Beckman Coulter, Inc.) within $10 \mathrm{~min}$.

Cell proliferation assay. HepG2, HepT1 and HuH6 cells were plated in 96-well plates at a density of $2 \times 10^{3}$ cells/well. After they were allowed to settle for $24 \mathrm{~h}$, the cells were treated with increasing concentrations of LRA $(1-10 \mu \mathrm{M})$ for various durations. The CCK-8 assay (Dojindo Molecular Technologies Inc.), which is a sensitive colorimetric assay used for the determination of cell viability in cell proliferation assays, was used for quantification of the number of proliferating cells, according to the manufacturer's protocol. Briefly, the medium in each well was replaced with $10 \%$ CCK-8 solution $(10 \mu \mathrm{l} / 100 \mu \mathrm{l}) / \mathrm{media}(\mathrm{v} / \mathrm{v})$ for $2 \mathrm{~h}$ at $37^{\circ} \mathrm{C}$, after which, absorbance was measured at $450 \mathrm{~nm}$ using a standard plate reader (Beckman Coulter, Inc.). For the cell proliferation assay, wells that contained known numbers of viable cells were used to create a calibration curve.
Colony formation assay. For soft agar assays, a base layer of $1 \%$ (w/v) agarose (cat. no. 214220; Difco; BD Biosciences, Franklin Lakes, NJ, USA) mixed with cell culture medium was plated into 6-well plates and allowed to solidify. The $1.5 \mathrm{ml}$ top agar layer, which was added on the top of the base layer, was made of $0.3 \%$ agar and media solution, and the HepG2, HepT1 and HuH6 cells cultured in regular medium were washed, counted and added to the mixture at $1 \times 10^{4}$ cells/well with increasing concentrations of LRA $(1-10 \mu \mathrm{M})$ at $37^{\circ} \mathrm{C}$ for 21 days. Culture medium $(500 \mu \mathrm{l})$ was added on top of the agarose to prevent drying of the soft agar. Cells were grown at $37^{\circ} \mathrm{C}$. Cells were treated with $1 \mathrm{ml} 5 \mathrm{mg} / \mathrm{ml} \mathrm{MTT}$ (cat. no. M5655; Sigma-Aldrich; Merck KGaA) per well for $2 \mathrm{~h}$ after 21 days of growth. All experiments were conducted in triplicate, and the means and standard deviation were determined. One-way ANOVA followed by Dunnett's multiple comparison post hoc test was used to determine statistical significance.

Forclonogenic assays, the cells were plated at 5,000 cells/well in 6-well culture dishes and left to form colonies over a period of 3 weeks. The colonies produced were fixed with methanol and stained with $0.05 \%$ crystal violet dye (cat. no. C3886; Sigma-Aldrich; Merck KGaA) for $10 \mathrm{~min}$, and the number of colonies was scored to determine the colony-forming ability of the cells. Colonies containing $>30$ cells were counted. Images of the plates were also captured.

Propidium iodide (PI) staining and flow cytometric analysis of the cell cycle. HepG2 and HuH6 cells were cultured in 6-well plates at $3 \times 10^{5}$ cells/well overnight and were then treated for $24 \mathrm{~h}$ with LRA at a final concentration of 0,1 or $10 \mu \mathrm{M}$. Subsequently, the cells were harvested, washed with PBS and fixed with $70 \%$ ethanol. The cells were then resuspended in PBS containing $100 \mu \mathrm{g} / \mathrm{ml}$ RNase A (Sigma-Aldrich; Merck KGaA) and $10 \mu \mathrm{g} / \mathrm{ml}$ PI for $30 \mathrm{~min}$ at room temperature. DNA content was determined by fluorescence-activated cell analysis of PI-stained cells on a LSR-II flow cytometer (BD Biosciences). Subsequently, analysis was performed using BD FACDiva software v. 6.0 (BD Biosciences) and FlowJo_v10 (FlowJo LLC, Ashland, OR, USA).

Statistical analysis. Statistical analysis was performed using GraphPad Prism 5 software (GraphPad Software, Inc., La Jolla, CA, USA). All values were presented as the means \pm standard deviation. One-way ANOVA and Dunnett's multiple comparison post hoc test, or Student'st-test (two-tailed) were used to analyze the differences between the experimental and control groups. $\mathrm{P}<0.05$ was considered to indicate a statistically significant difference. Half maximal inhibitory concentration $\left(\mathrm{IC}_{50}\right)$ values were calculated using nonlinear regression in GraphPad Prism.

\section{Results}

LRH-1 expression is increased in hepatoblastoma cell lines. To explore the role of LRH-1 in hepatoblastoma, the expression levels of LRH-1 were detected in three hepatoblastoma cell lines, HepG2, HuH6 and HepT1, and one control cell line, THLE-2. The THLE-2 cell line consists of epithelial cells from the left liver lobe transformed with SV40 large T 
A

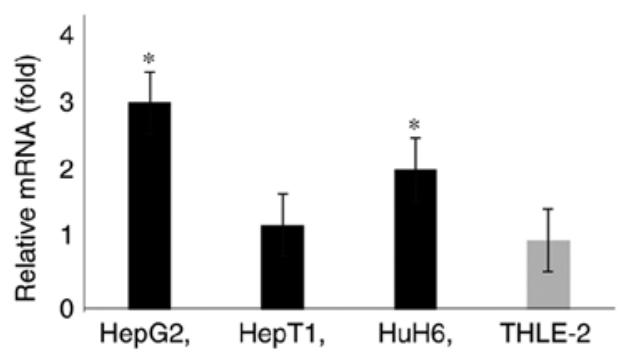

B

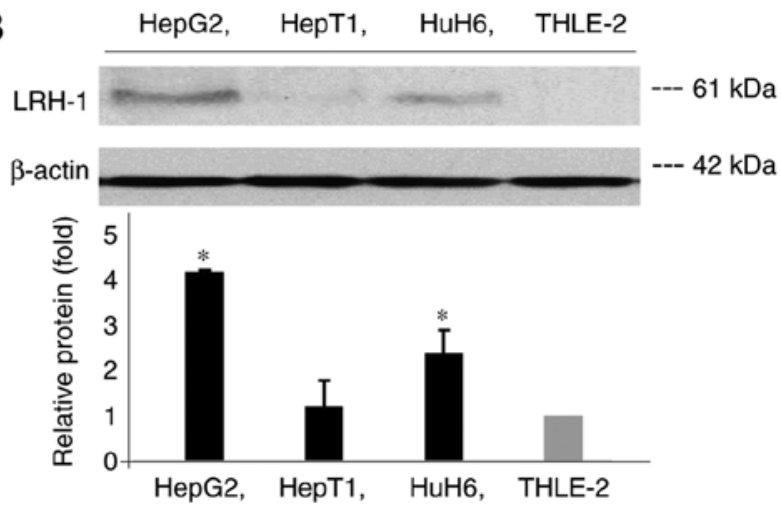

Figure 1. Expression of LRH-1 in human hepatoblastoma cell lines. (A) mRNA expression levels of LRH-1 in HepG2, HuH6, HepT1 and THLE-2 cells. mRNA levels were determined by reverse transcription-quantitative polymerase chain reaction. Data are presented as the means \pm standard deviation, $\mathrm{n}=3$ independent experiments. " $\mathrm{P}<0.05$ compared with the control THLE-2 cells. (B) Protein expression levels of LRH-1 in hepatoblastoma cell lines were determined by western blotting. $\beta$-actin was used as a control protein to determine relative expression levels. Relative protein expression is shown in the lower panel. Data are presented as the means \pm standard deviation, $\mathrm{n}=3$ independent experiments. ${ }^{*} \mathrm{P}<0.05$ compared with the control THLE- 2 cells. LRH-1, liver receptor homolog-1.

antigen. The RT-qPCR analysis demonstrated that the mRNA expression levels of LRH-1 were significantly increased in HepG2 and HuH6 cells compared with in HepT1 and THLE-2 cells (Fig. 1A). Western blot analysis also revealed a similar expression pattern of LRH-1 protein in these cell lines (Fig. 1B).

Knockdown of LRH-1 decreases cell proliferation via the suppression of CCNDI and $c-M y c$ expression in hepatoblastoma cells. To examine whether silencing LRH-1 inhibits hepatoblastoma cell proliferation, stable LRH-1 knockdown cell lines were generated using lentiviral-based shRNAs in HepG2 and HuH6 cells. RT-qPCR and western blot analyses were conducted to verify the effectiveness of the shRNA sequences; shRNA3 was revealed to the most efficient, clearly depleting LRH-1 at the mRNA and protein levels (Fig. 2A-C). Therefore, shRNA3 was used for the subsequent experiments. Since HepT1 had low baseline LRH-1 expression, the effects of shLRH-1 were only detected on HepG2 and HuH6 cells. RT-qPCR analyses demonstrated that the mRNA expression levels of LRH-1 were reduced by $70-80 \%$ in response to shLRH-1 in both HepG2 and HuH6 cells compared with the vector control shRNA (shCTL) cells (Fig. 2A and D). Furthermore, western blot analysis revealed that the protein expression levels of LRH-1 were significantly reduced in shLRH-1 cells by $\sim 80 \%$ compared with the shCTL cells (Fig. 2C and E).

To determine whether knockdown of LRH-1 had an inhibitory effect on hepatoblastoma cell growth, CCK-8 assays were conducted with HepG2 and HuH6 cells infected with shLRH-1 compared with cells infected with shCTL. After 5 days, both shLRH-1 cell lines exhibited significant decreases in cell proliferation (Fig. 2F and G). Colony formation assays were performed to determine the long-term effects of LRH-1 knockdown on the proliferation of hepatoblastoma cells. After 3 weeks, there were significantly fewer colonies $(\mathrm{P}<0.05)$ of HepG2 and HuH6 shLRH-1 cells compared with the shCTL cells (Fig. $2 \mathrm{H}$ and I). Taken together, these results indicated that LRH-1 may serve an important role in hepatoblastoma cell proliferation, since specific knockdown of LRH-1 with
shRNA resulted in the inhibition of proliferation and colony formation in vitro.

It has been demonstrated that LRH-1 regulates the expression of the cell cycle proteins CCND1 $(14,15)$, CCNE1 $(14,15)$ and c-Myc (15). To explore the molecular mechanisms by which LRH-1 regulates hepatoblastoma cell proliferation, RT-qPCR and western blot analyses were performed on HepG2 and HuH6 shLRH-1 and shCTL cells. The results demonstrated that the mRNA and protein expression levels of CCND1 and c-Myc were significantly decreased in response to LRH-1 knockdown, whereas no marked alterations were observed in CCNE1 expression following LRH-1 knockdown (Fig 3A-D). These results suggested that LRH-1 knockdown-induced decreases in cell proliferation may be associated with the downregulation of CCND1 and c-Myc in hepatoblastoma cells.

LRA inhibits cell viability, proliferation and anchorageindependent growth. In order to determine the anticancer effects of targeting LRH-1 in hepatoblastoma cells, the specific LRH-1 antagonist LRA was used (20). Cell viability assays were performed to determine the $\mathrm{IC}_{50}$ values at which HepG2, HuH6 and HepT1 hepatoblastoma cells respond to LRH-1 inhibition. The results revealed that the treatment markedly reduced the cell viability of all three hepatoblastoma cell lines in a dose-dependent manner, although HepT1 was relatively resistant to LRA treatment, compared with cells treated with vehicle (DMSO) only. Specifically, the $\mathrm{IC}_{50}$ values of LRA in hepatoblastoma cell lines were $40.11 \mu \mathrm{M}$ in HepG2, 29.66 $\mu \mathrm{M}$ in HuH6 and 53.23 $\mu \mathrm{M}$ in HepT1 cells (Fig. 4A and B).

The present study also aimed to determine if LRA could inhibit cell proliferation of the three hepatoblastoma cell lines at sub-IC ${ }_{50}$ concentrations. HepG2, HepT1 and HuH6 cells were exposed to lower doses of LRA and their growth was observed for 7 days. LRA induced dose-dependent inhibition of HepG2 and HuH6 cell proliferation; these were the two cell lines in which baseline LRH-1 expression levels were high. Specifically, in these two cell lines, the proliferation rates were significantly decreased after 5 days of exposure to $10 \mu \mathrm{M}$ LRA and after 7 days of exposure to $1 \mu \mathrm{M}$ LRA (Fig. 4C). However, HepT1 cells, which had a lower baseline expression of LRH-1, 
A

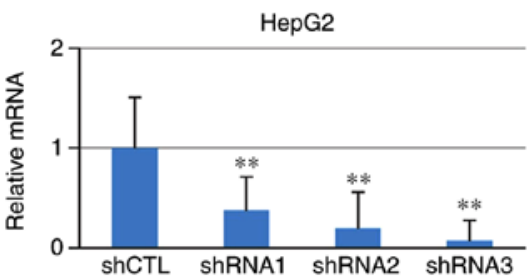

B

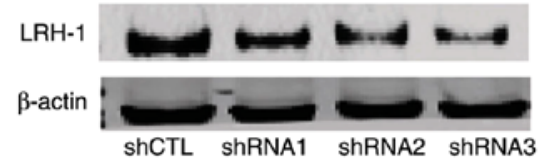

C
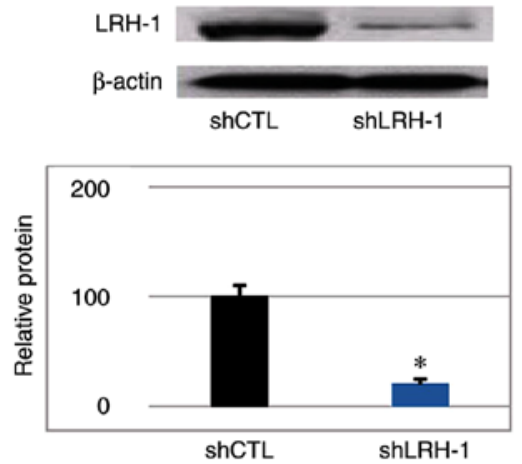

F

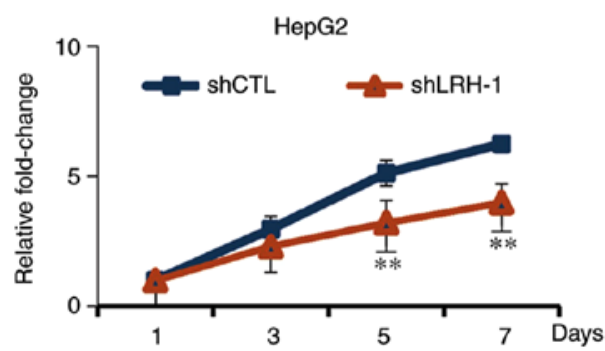

$\mathrm{H}$
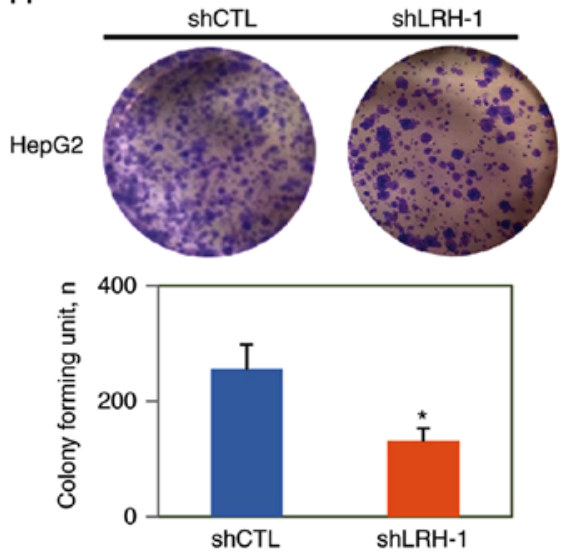

D

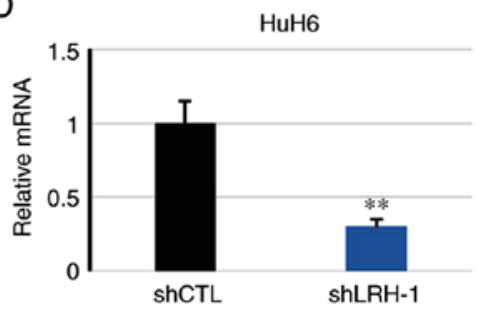

E
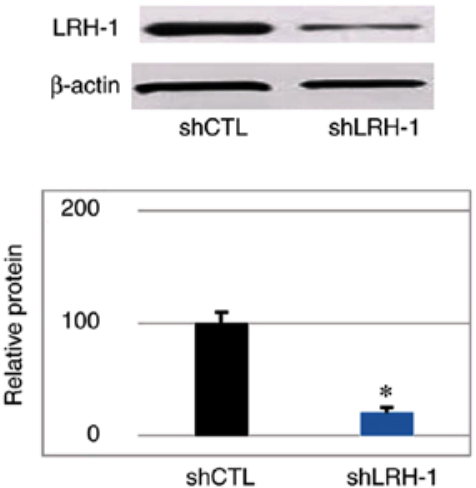

G

HuH6

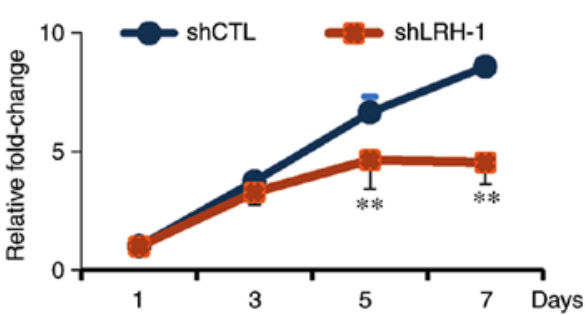

I
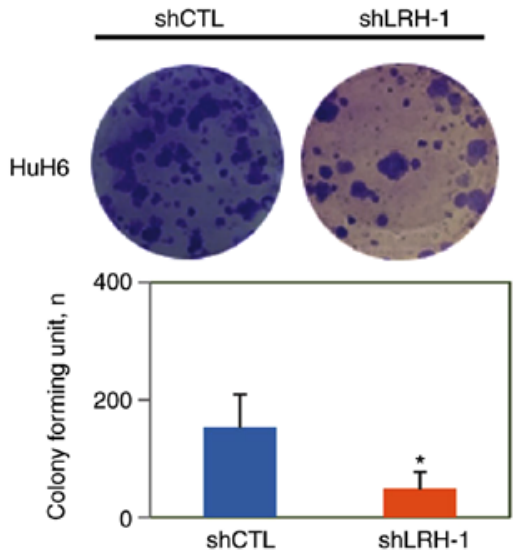

Figure 2. Lentivirus-mediated shRNA suppresses LRH-1 expression, and inhibits proliferation and colony formation in hepatoblastoma cells. (A and D) mRNA expression levels of LRH-1 were determined by reverse transcription-quantitative polymerase chain reaction in HepG2 and HuH6 cells infected with shCTL or shLRH-1. Data are presented as the means \pm standard deviation, $\mathrm{n}=3-5$ independent experiments. ${ }^{*} \mathrm{P}<0.05$ compared with the shCTL group. (B, C and E) Western blotting was performed using (B and C) HepG2 and (E) HuH6 cells infected with shCTL or shLRH-1. $\beta$-actin was used as a control protein to determine relative expression levels. Data are presented as the means \pm standard deviation, $\mathrm{n}=3$ independent experiments. ${ }^{*} \mathrm{P}<0.05$ compared with the shCTL group. (F and G) Proliferation of HepG2 and HuH6 cells infected with shCTL or shLRH-1 was assessed using Cell Counting Kit-8 assays. Data are presented as the means \pm standard deviation. "P $<0.05,{ }^{* *} \mathrm{P}<0.01$ compared with the shCTL group. (H and I) Colony formation assays were performed using HepG2 and HuH6 cells infected with shCTL or shLRH-1. The colonies were stained with crystal violet and images were captured. Quantification of the number of colonies is shown in the lower panels. Data are presented as the means \pm standard deviation, $\mathrm{n}=3$ independent experiments. " $\mathrm{P}<0.05$ compared with the shCTL group 5 . CTL, control; LRH-1, liver receptor homolog-1; sh/shRNA, short hairpin RNA. 
A

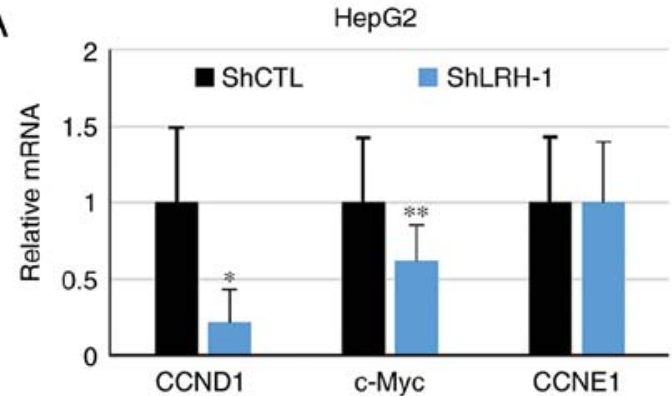

C
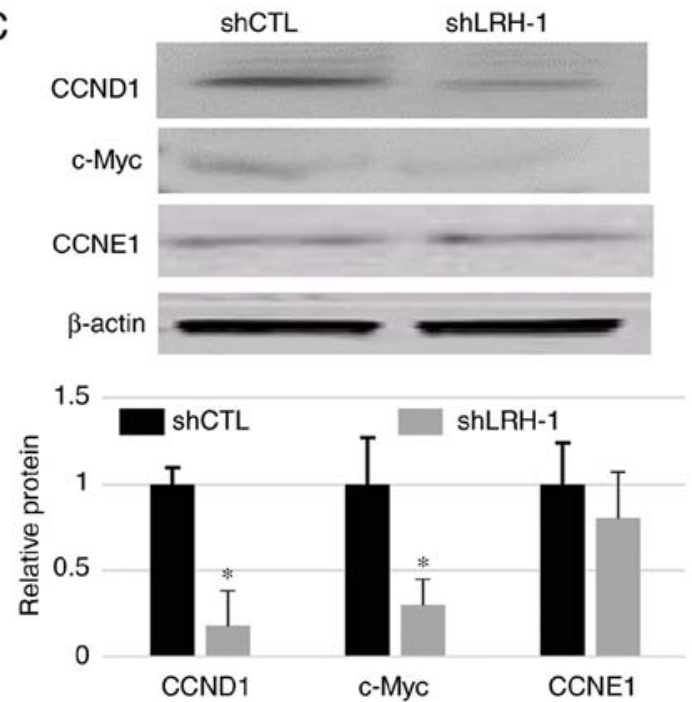

B

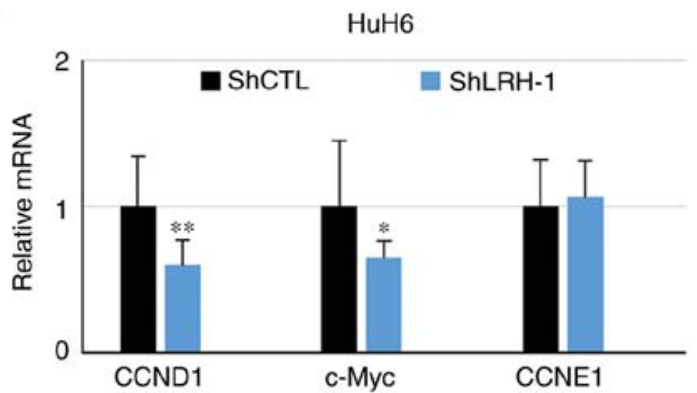

D
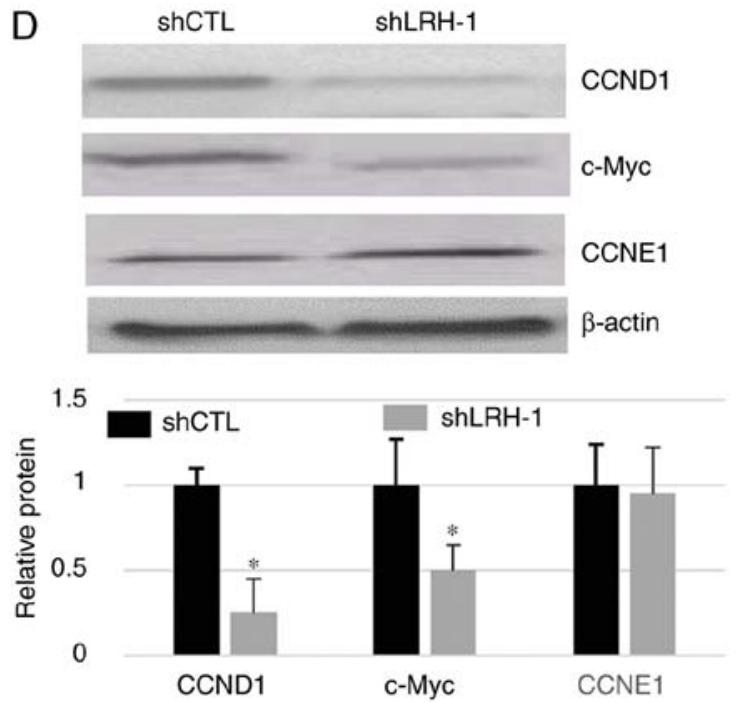

Figure 3. Silencing LRH-1 gene expression affects cell cycle gene expression in hepatoblastoma cells. (A and B) mRNA expression levels of CCND1, CCNE1 and c-Myc in shCTL and shLRH-1 cells, as determined by reverse transcription-quantitative polymerase chain reaction. ${ }^{*} \mathrm{P}<0.05$, ${ }^{* *} \mathrm{P}<0.001$ compared with the shCTL group 1. (C and D) CCND1, CCNE1 and c-Myc protein expression levels were determined by western blotting in shLRH-1 and shCTL HepG2 and HuH6 cells. Relative protein expression levels are shown in the lower panels. Data are presented as the means \pm standard deviation, $n=3$ independent experiments. ${ }^{*} \mathrm{P}<0.05$ compared with the shCTL group. CCND1, cyclin D1; CCNE1, cyclin E1; CTL, control; LRH-1, liver receptor homolog-1; sh, short hairpin RNA.

were less sensitive to LRA treatment; the proliferation rate in these cells was significantly decreased only after 7 days of exposure to $10 \mu \mathrm{M}$ LRA (Fig. 4C). These data indicated that LRA may inhibit hepatoblastoma cell proliferation as both a cytotoxic and cytostatic agent.

Cancer cells have the unique ability to grow in soft agar without being anchored to a surface. Therefore, the present study evaluated the effects of LRA on this anchorage-independent growth capability using soft agar growth assays. HepG2, HuH6 and HepT1 hepatoblastoma cells growing on soft agar were treated with increasing concentrations of LRA for 3 weeks, after which, their ability to form colonies was assessed, as compared with the vehicle-treated control cells. Following treatment with LRA, colony formation was significantly decreased in all tested hepatoblastoma cells in a dose-dependent manner (Fig. 4D and E), thus suggesting that LRA impaired anchorage-independent growth of hepatoblastoma cells.

LRA inhibits cell proliferation through downregulation of CCND1 and c-Myc in hepatoblastoma cell lines. LRH-1 is known to function upstream of CCND1, CCNE1 and c-Myc. Therefore, it was hypothesized that the effects of LRA on hepatoblastoma cell lines were induced through one or more of these proteins. To test this hypothesis, the expression levels of these proteins were detected in HepG2 and HuH6 hepatoblastoma cells incubated with increasing doses of LRA for $24 \mathrm{~h}$. Western blot analyses of these proteins revealed that LRA dose dependently inhibited CCND1 and c-Myc expression, whereas LRA did not seem to markedly affect expression levels in HepT1 cells (Fig. 5A and B). To further determine whether LRA affects the cell cycle, HepG2 and HuH6 cells exposed to various concentrations of LRA for $24 \mathrm{~h}$ were stained with PI and subjected to flow cytometry for cell cycle analysis. Following LRA treatment, the percentage of cells in $G_{1} / G_{0}$ phase was increased in both cell lines, thus indicating that LRA treatment may lead to cell cycle arrest in hepatoblastoma cells (Fig. 5C and D). These results suggested that LRA may inhibit hepatoblastoma cell proliferation by inhibiting CCND1 and c-Myc expression, and by inducing cell cycle arrest at $\mathrm{G}_{1}$ phase.

To further confirm that the LRH-1 downstream targets, CCND1 and c-Myc, decreased proliferation of hepatoblastoma cells, the present study examined whether silencing CCND1 and c-Myc inhibited hepatoblastoma cell proliferation. Stable CCND1 and c-Myc knockdown cell lines were generated using lentiviral-based shRNAs in HepG2 and HuH6 cells. Western blot analyses were conducted to verify the effectiveness of the shRNA sequences (Fig. 6A and B). To determine whether knockdown of CCND1 and c-Myc exerted an inhibitory effect on HepG2 and HuH6 hepatoblastoma cell growth, CCK-8 assays were conducted. After 7 days, both CCND1 and 
A

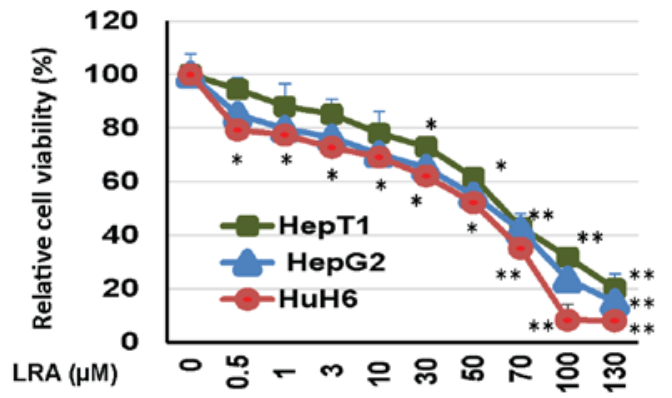

C
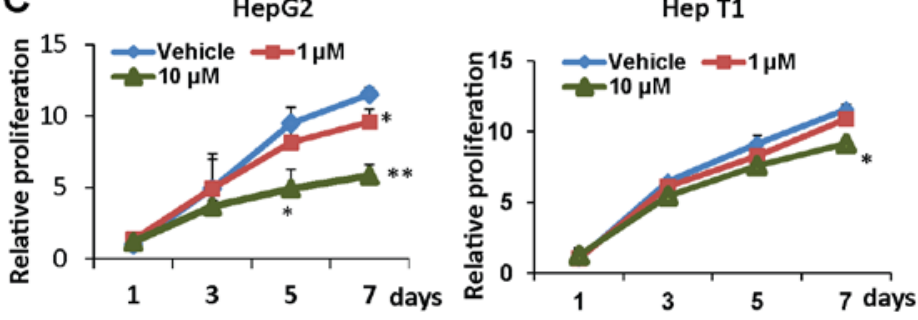

B
$I_{50}$ of LRA in HB cell lines

\begin{tabular}{|c|c|}
\hline Cell lines & IC50 $(\mu \mathrm{M})$ \\
\hline HepG2 & 40.11 \\
\hline HepT1 & 53.23 \\
\hline HuH6 & 29.66 \\
\hline
\end{tabular}

HuH6

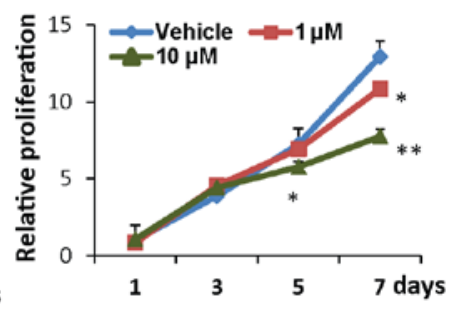

E

D

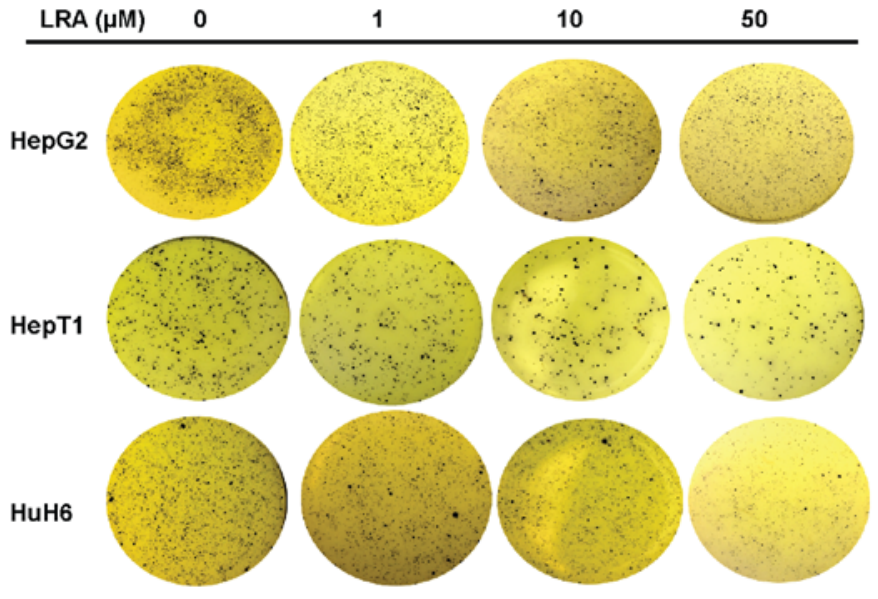

E
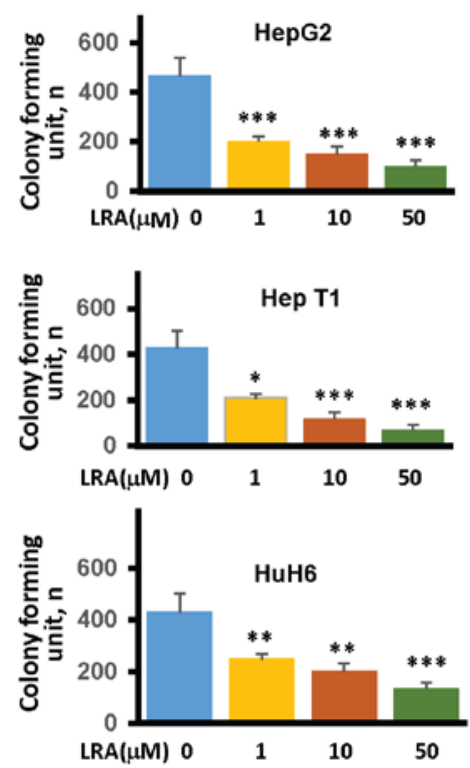

Figure 4. LRA inhibits cell viability, proliferation and soft agar colony formation of hepatoblastoma cells. (A) HepG2, HepT1 and HuH6 cells were plated in 96-well flat-bottomed plates and were treated with increasing concentrations of LRA for $72 \mathrm{~h}$. Cytotoxic activity was determined with CCK-8 assays. Data are presented as the means \pm standard deviation, $n=3-5$ independent experiments. ${ }^{*} \mathrm{P}<0.05,{ }^{* *} \mathrm{P}<0.01$ compared with vehicle-treated cells. (B) $\mathrm{IC}_{50}$ values of LRA in hepatoblastoma cell lines. (C) HepG2, HepT1 and HuH6 cells were treated with LRA at the indicated concentrations. Cell proliferation was detected by CCK- 8 assays. Data are presented as the means \pm standard deviation, $n=3-5$ independent experiments. ${ }^{*} \mathrm{P}<0.05,{ }^{* *} \mathrm{P}<0.01$, as analyzed by ANOVA multiple comparison analysis testing. (D) HepG2, HepT1 and HuH6 cells were seeded in 6-well plates with LRA $(0,1,10$ and $50 \mu \mathrm{M})$, media and agar, and were grown for 3 weeks. The colonies were stained with MTT and images were captured. (E) Colonies were counted and are presented as the means \pm standard deviation, $\mathrm{n}=3$ independent experiments. ${ }^{* * *} \mathrm{P}<0.01,{ }^{* * * *} \mathrm{P}<0.001 ; \mathrm{IC}_{50}$, half maximal inhibitory concentration; LRA, LRH-1 antagonist; LRH-1, liver receptor homolog-1.

c-Myc knockdown cell lines exhibited significant decreases in cell proliferation compared with cells infected with shCTL (Fig. 6C and D).

LRA significantly enhances the cytotoxic effects of dox on hepatoblastoma cells. It is well known that monotherapies are less effective in the treatment of high-risk cancer, due to the acquisition of chemoresistance to drugs after prolonged exposure. Therefore, the present study evaluated the effects of LRA in combination with the established chemotherapeutic drug dox (5). Cell viability assays were conducted on HepG2 and HuH6 cells treated with $10 \mu \mathrm{M}$ LRA and increasing doses of dox, in order to determine if LRH-1 inhibition affected the responsiveness of cells to chemotherapy. Notably, the viability of these hepatoblastoma cell lines was much lower following combination treatment compared with dox treatment alone (Fig. 7). These data indicated that LRA enhanced the cytotoxicity of dox in hepatoblastoma cells.

\section{Discussion}

Numerous studies have suggested that inhibition of LRH-1 signaling is effective in the treatment of breast, pancreatic and endometrial cancer $(12,14,16)$. The present results demonstrated that LRH-1 was upregulated in HepG2 and 
A

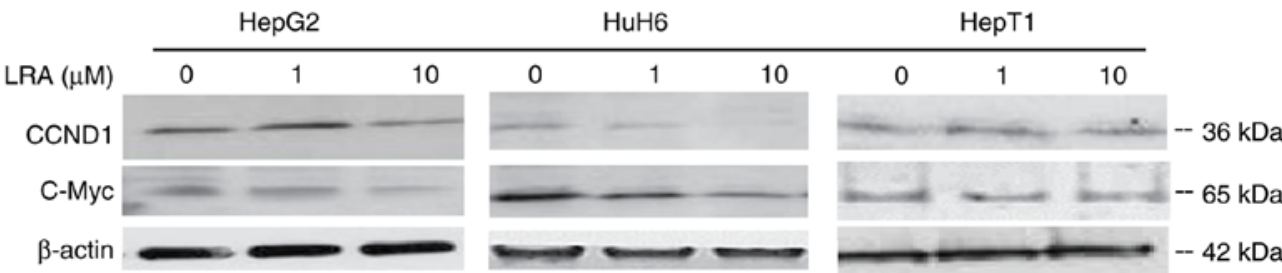

B
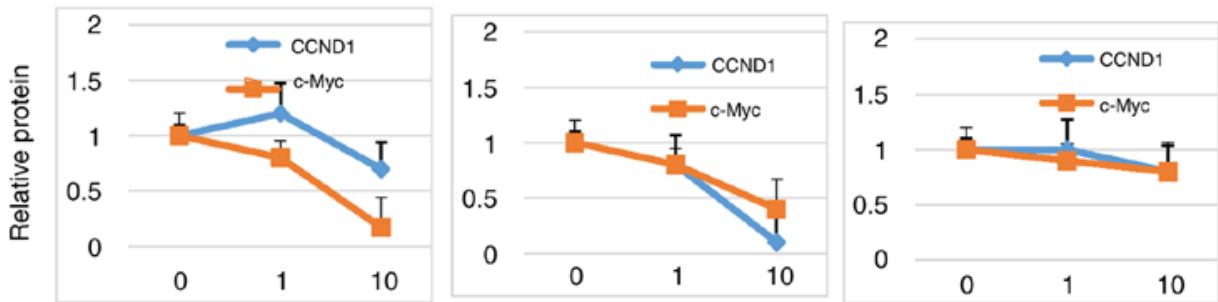

C

Vehicle control

$1 \mu \mathrm{M} \mathrm{LRA}$

$10 \mu \mathrm{M}$ LRA
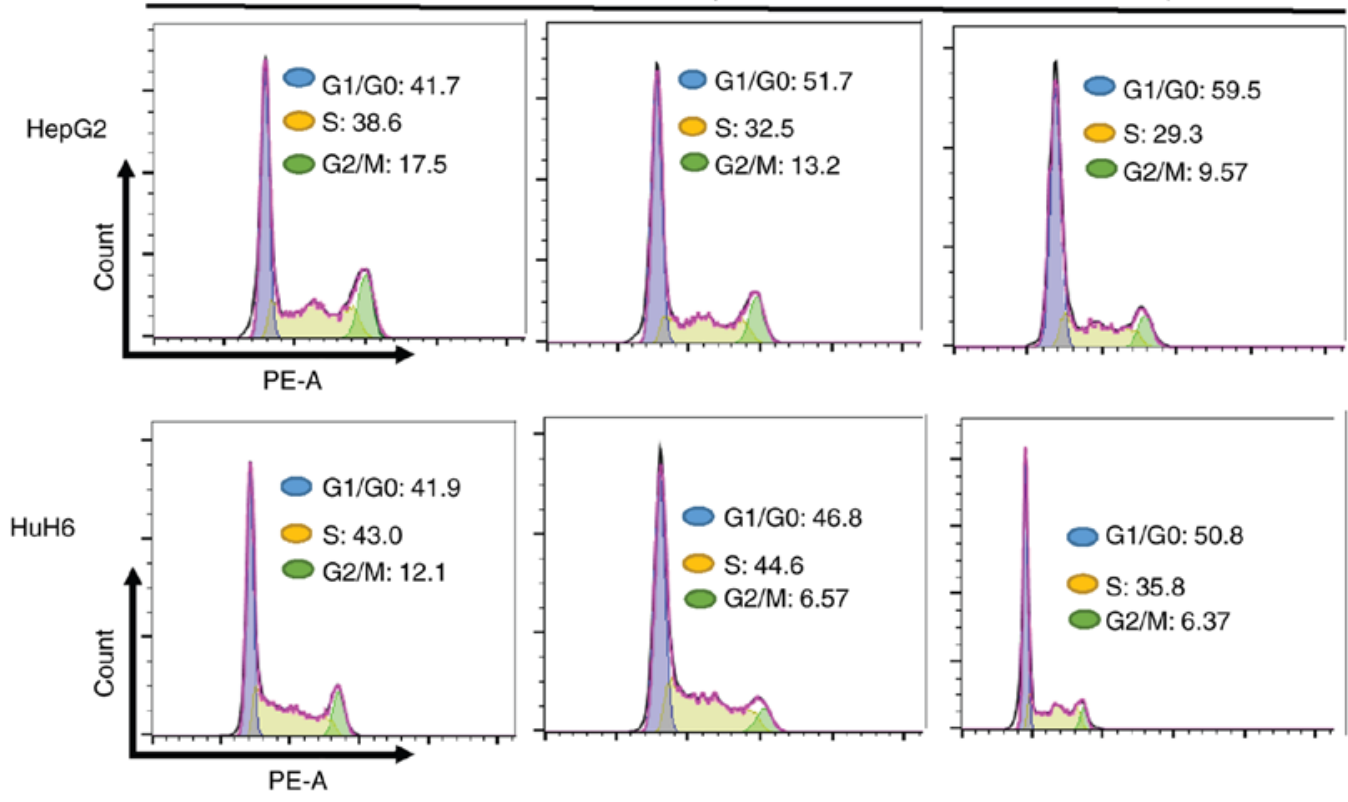

D
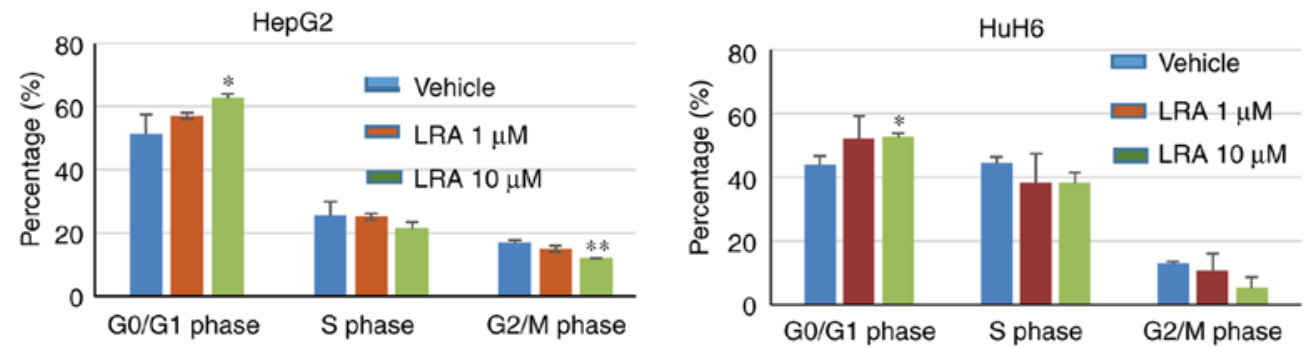

Figure 5. LRA treatment markedly decreases CCND1 and c-Myc expression, and induces cell cycle arrest at $\mathrm{G}_{1}$ phase in hepatoblastoma cells. (A) Western blot analyses of the protein expression levels of CCND1 and c-Myc after incubation with LRA for $24 \mathrm{~h}$ in HepG2, HepT1 and HuH6 cells. (B) Relative protein expression levels. Data are presented as the means \pm standard deviation, $n=3$ independent experiments. (C) Representative histograms of cell-cycle distribution in HepG2 and Huh6 cell lines. Cells were preincubated with LRA for $24 \mathrm{~h}$ and stained with PI; cell cycle progression was then analyzed by flow cytometry. (D) Summary of PI staining. Data are presented as the means \pm standard deviation. $\mathrm{n}=3$ independent experiments. " $\mathrm{P}<0.05$. CCND1, cyclin D1; CCNE1, cyclin E1; LRA, LRH-1 antagonist; LRH-1, liver receptor homolog-1.

HuH6 human hepatoblastoma cells compared with the control THLE-2 cells; this finding is similar to the results of a previous report studying pancreatic cancer cell lines and human tumor samples (14). In addition, silencing LRH-1 by shRNA inhibited cell proliferation and colony formation of HepG2 and HuH6 cells, and, to a lesser extent, HepT1 cells, which have lower baseline levels of LRH-1. Subsequently, LRH-1 was inhibited with the antagonist LRA, and the results indicated that LRA may work as a cytostatic drug, blocking cell proliferation through the suppression of CCND1 and c-Myc. Notably, HepT1, the tested cell line with the lowest endogenous levels of LRH-1, exhibited less sensitivity to LRA. Taken together, these findings indicated that cells with higher expression levels of LRH-1 may be more susceptible to LRH-1 inhibition.

Transcriptional targets of LRH-1 include c-Myc, and the cell cycle regulators CCND1 and CCNE1, and these three 
A

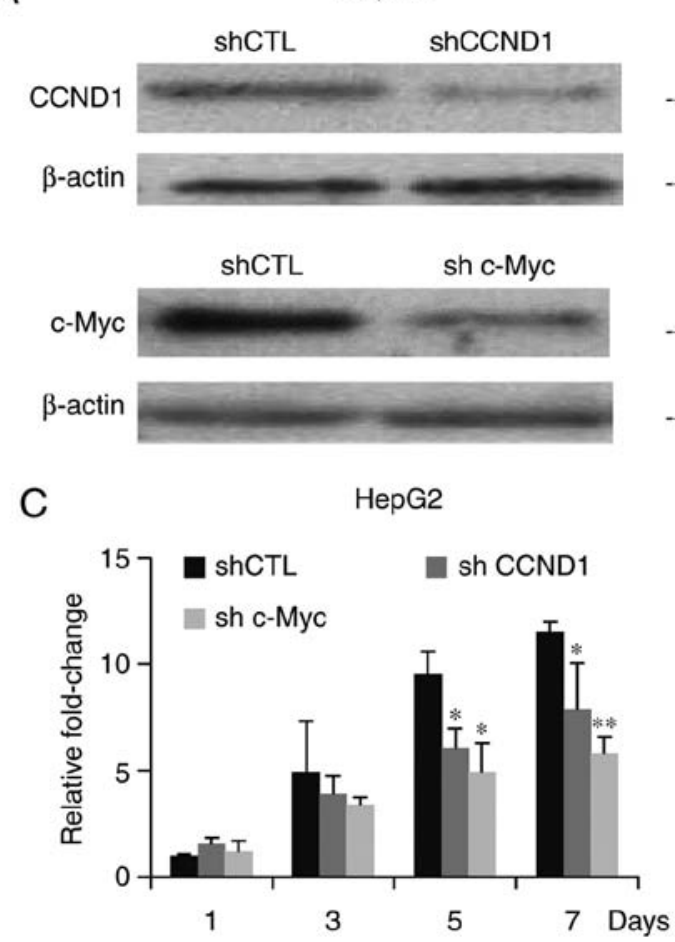

B

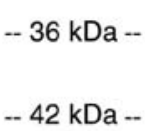

- $65 \mathrm{kDa}--$

$-42 \mathrm{kDa}-$
HuH6

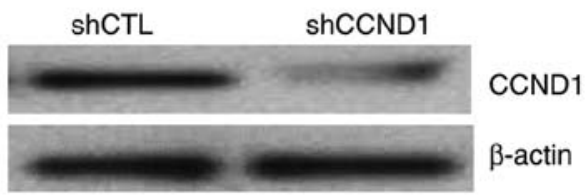

shCTL

sh c-Myc

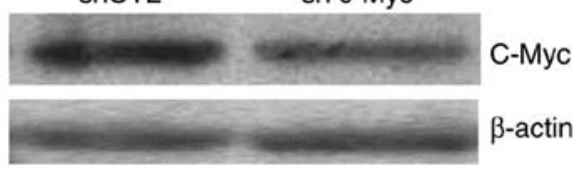

$\mathrm{HuH6}$

D

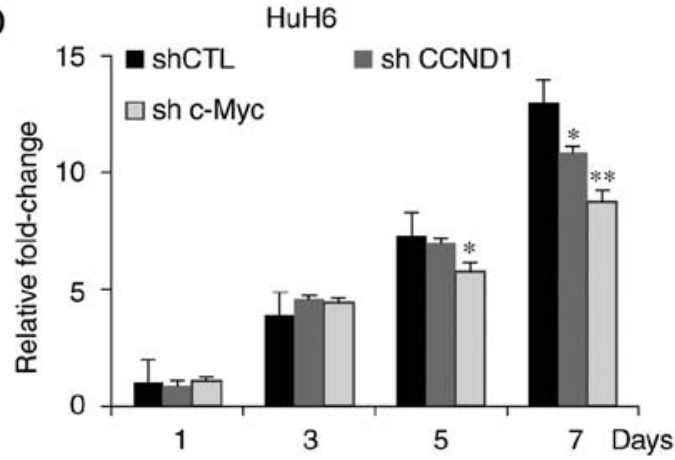

Figure 6. Lentivirus-mediated shRNA suppresses CCND1 and c-Myc expression, and inhibits proliferation. (A and B) Western blotting was performed on HepG2 and HuH6 cells infected with shCTL, shCCND1 or shc-Myc. $\beta$-actin was used as a control protein to determine relative expression levels. (C and D) Proliferation of HepG2 and HuH6 cells infected with shCTL, shCCND1 or shc-Myc, as assessed with Cell Counting Kit-8 assays. Data are presented as the means \pm standard deviation, $\mathrm{n}=3$ independent experiments. ${ }^{*} \mathrm{P}<0.05,{ }^{* * *} \mathrm{P}<0.01$. CCND1, cyclin D1; CTL, control; LRH-1, liver receptor homolog-1; sh/shRNA, short hairpin RNA.

A

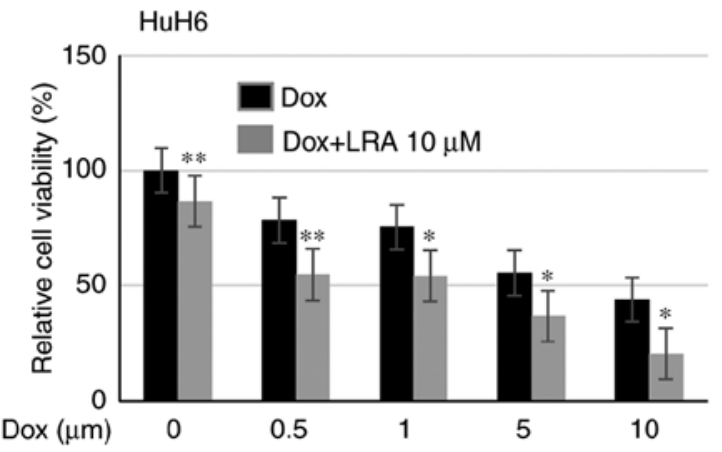

B

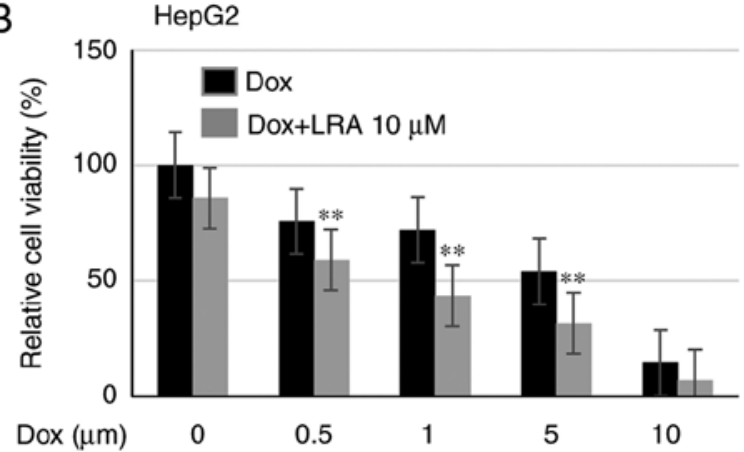

Figure 7. LRA treatment enhances the cytotoxic effects of dox on hepatoblastoma cells. (A and B) LRA enhanced the cytotoxic effects of dox. HepG2 and HuH6 cells were seeded in 96-well plates and treated with $10 \mu \mathrm{M}$ LRA combined with increasing concentrations of sorafenib or dox (0-10 $\mu \mathrm{M})$ for $48 \mathrm{~h}$. Cell viability was measured by MTT assays. Data are presented as the means \pm standard deviation, $n=3$ independent experiments. ${ }^{*} \mathrm{P}<0.05,{ }^{* * *} \mathrm{P}<0.01$. Dox, doxorubicin; LRA, LRH-1 antagonist; LRH-1, liver receptor homolog-1.

genes are known to control cell differentiation, growth and proliferation. Both CCND1 and CCNE1 are frequently overexpressed in gastrointestinal tumors and contribute to oncogenesis in animal models $(15,23,24)$. c-Myc is a potent oncogene that promotes tumorigenesis in various tissues, and its overexpression predicts poor clinical outcomes (25). Other downstream targets of LRH-1 include calpain 1, which upregulates the expression of CCNE1 truncated T1/T2 isoforms (14) and Nanog, which serves a critical role in the reprograming of murine somatic cells to pluripotent cells (26). In addition, scavenger receptor class B member 1, low-density lipoprotein receptor and steroidogenic acute regulatory protein are downstream targets of LRH-1 in the progesterone synthesis pathway in ovulation (27).

In hepatoblastoma, downregulation of LRH-1 by lentiviral shRNAs or inhibition of LRH-1 by LRA resulted in a decrease in the mRNA and protein expression levels of CCND1 and c-Myc, which may lead to the inhibition of cell proliferation and colony formation. However, significant alterations were not detected in CCNE1; these findings differ from the results observed in pancreatic and colon cancer (28). In different cell types, diverse effects can be seen on gene and protein expression. For example, varying effects on CCNE1 expression may be due to different regulation of the downstream LRH-1 
signaling pathways. CCND1 inhibition-mediated cell cycle arrest at the $\mathrm{G}_{1}$ phase is likely one of the major underlying mechanisms of action of LRA. In addition, suppression of c-Myc by LRA may contribute to the observed suppression of hepatoblastoma cell proliferation.

Development of novel targeted drugs is integral to overcoming chemoresistance and improving the survival of patients with hepatoblastoma. In order to identify a novel therapy, the present study investigated the effects of LRA on hepatoblastoma growth. LRA was able to decrease hepatoblastoma cell proliferation in vitro, when used as a single agent. It was therefore hypothesized that LRA may be combined with other chemotherapeutic agents that regulate different signaling pathways to sensitize tumors to various forms of therapy, impair tumor cell escape mechanisms and increase efficacy for patients with hepatoblastoma. The present study evaluated the effects of combination therapy of LRA with dox, which is an anticancer drug that intercalates into DNA and inhibits macromolecular biosynthesis. LRA enhanced the cytotoxic effects of dox on hepatoblastoma cells. Based on these findings, it is possible that LRA treatment may sensitize patients to chemotherapy and thus decrease drug toxicity by allowing lower concentrations of drug to be used.

Notably, HepT1 cells possessed lower levels of LRH-1, which may be due to the involvement of other upstream regulators. In PCR-based microsatellite analysis of chromosome arm 11p, a loss of heterozygosity at all informative loci, including the Wilms tumor 1 homolog and insulin-like growth factor 2 genes, was detected (29), which may explain why HepT1 cells behave differently to other cells. It has previously been reported that HepG2 and HuH6 hepatoblastoma cell lines accurately resemble primary human hepatoblastoma samples to varying degrees, and the HepG2 cell line most accurately mimics human hepatoblastoma (22).

In conclusion, the present results suggested that LRH-1 may contribute to cell proliferation in hepatoblastoma. Hepatoblastoma cells with higher LRH-1 expression levels were more susceptible to LRH-1 inhibition. In addition, it was revealed that LRA may behave as a cytostatic compound at low concentrations, and it may inhibit hepatoblastoma cell proliferation through the suppression of CCND1 and c-Myc expression. LRA also exhibited cytotoxic effects at higher concentrations. Furthermore, LRA induced cell cycle arrest at $G_{1}$ phase, and inhibited colony forming ability and tumor growth. Analysis of a panel of hepatoblastoma cell lines provided compelling evidence to suggest that LRH-1 may serve an important role in the progression of hepatoblastoma and implicated LRA as a novel potential agent for innovative therapeutic strategies against hepatoblastoma. LRA might serve as an effective drug in potential clinical trials for patients with recurrent or refractory hepatoblastoma, particularly in patients resistant to dox. Therefore, LRA may be considered a promising novel candidate for innovative therapeutic strategies against hepatoblastoma.

\section{Acknowledgements}

The authors would like to thank Dr. Amos Gaikward and Dr. Tatiana Goltsova (Baylor College of Medicine, Texas Children's Hospital, Houston, TX, USA) for their assistance with flow cytometry.

\section{Funding}

The present study was supported by the Texas Children's Department of Surgery Seed Grant (S.V.) and the Macy Easom Cancer Research Foundation Grant (S.V.).

\section{Availability of data and materials}

The datasets used and/or analyzed during the current study are available from the corresponding author on reasonable request.

\section{Authors' contributions}

JiJ and SAV designed and performed the experiments regarding the activity of LRA. JuJ, SEW, RHP, YS, NGJ, BL, WS, XC and YY designed and performed the experiments regarding the LRH-1 expression and activity of LRA. JiJ and SAV generated the ideas, supervised the study, and wrote the paper. All authors read and approved the final manuscript.

\section{Ethics approval and consent to participate}

Not applicable.

\section{Patient consent for publication}

Not applicable.

\section{Competing interests}

The authors declare that they have no competing interests.

\section{References}

1. Buendia MA: Unravelling the genetics of hepatoblastoma: Few mutations, what else? J Hepatol 6: 1202-4, 2014.

2. von Schweinitz D: Hepatoblastoma: Recent developments in research and treatment. Semin Pediatr Surg 21: 21-30, 2012

3. von Schweinitz D: Management of liver tumors in childhood. Semin Pediatr Surg 15: 17-24, 2006.

4. Schmid I, Haberle B, Albert MH, Corbacioglu S, Fröhlich B, Graf N, Kammer B, Kontny U, Leuschner I, Scheel-Walter HG, et al: Sorafenib and cisplatin/doxorubicin (PLADO) in pediatric hepatocellular carcinoma. Pediatr Blood Cancer 58: 539-544, 2012.

5. Malogolowkin MH, Katzenstein HM, Krailo M, Chen Z, Quinn JJ, Reynolds M and Ortega JA: Redefining the role of doxorubicin for the treatment of children with hepatoblastoma. J Clin Oncol 26: 2379-2383, 2008.

6. Warmann SW, Armeanu S, Frank H, Buck H, Graepler F, Lemken ML, Heitmann H, Seitz G, Lauer UM, Bitzer M and Fuchs J: In vitro gene targeting in human hepatoblastoma. Pediatr Surg Int 22: 16-23, 2006.

7. Warmann S, Hunger M, Teichmann B, Flemming P, Gratz KF and Fuchs J: The role of the MDRl gene in the development of multidrug resistance in human hepatoblastoma: Clinical course and in vivo model. Cancer 95: 1795-1801, 2002.

8. Fayard E, Auwerx J and Schoonjans K: LRH-1: An orphan nuclear receptor involved in development, metabolism and steroidogenesis. Trends Cell Biol 14: 250-260, 2004.

9. Fayard E, Schoonjans K, Annicotte JS and Auwerx J: Liver receptor homolog 1 controls the expression of carboxyl ester lipase. J Biol Chem 278: 35725-35731, 2003.

10. Petersen GM, Amundadottir L, Fuchs CS, Kraft P, StolzenbergSolomon RZ, Jacobs KB, Arslan AA, Bueno-de-Mesquita HB, Gallinger S, Gross M, et al: A genome-wide association study identifies pancreatic cancer susceptibility loci on chromosomes 13q22.1, 1q32.1 and 5p15.33. Nat Genet 42: 224-228, 2010. 
11. Annicotte JS, Fayard E, Swift GH, Selander L, Edlund H, Tanaka T, Kodama T, Schoonjans $\mathrm{K}$ and Auwerx $\mathrm{J}$ : Pancreatic-duodenal homeobox 1 regulates expression of liver receptor homolog 1 during pancreas development. Mol Cell Biol 23: 6713-6724, 2003.

12. Thiruchelvam PT, Lai CF, Hua H, Thomas RS, Hurtado A, Hudson W, Bayly AR, Kyle FJ, Periyasamy M and Photiou A: The liver receptor homolog-1 regulates estrogen receptor expression in breast cancer cells. Breast Cancer Res Treat 127: 385-396, 2011.

13. Bolado-Carrancio A, Riancho JA, Sainz J and Rodriguez-Rey JC: Activation of nuclear receptor NR5A2 increases Glut4 expression and glucose metabolism in muscle cells. Biochem Biophys Res Commun 446: 614-619, 2014.

14. Lin Q, Aihara A, Chung W, Li Y, Huang Z, Chen X, Weng S, Carlson RI, Wands JR and Dong X: LRH1 as a driving factor in pancreatic cancer growth. Cancer Lett 345: 85-90, 2014.

15. Botrugno OA, Fayard E, Annicotte JS, Haby C, Brennan T, Wendling O, Tanaka T, Kodama T, Thomas W, Auwerx J and Schoonjans K: Synergy between LRH-1 and beta-catenin induces G1 cyclin-mediated cell proliferation. Mol Cell 15: 499-509, 2004

16. Dube C, Bergeron F, Vaillant MJ, Robert NM, Brousseau C and Tremblay JJ: The nuclear receptors SF1 and LRH1 are expressed in endometrial cancer cells and regulate steroidogenic gene transcription by cooperating with AP-1 factors. Cancer Lett 275 127-138, 2009.

17. Whitby RJ, Stec J, Blind RD, Dixon S, Leesnitzer LM, Orband-Miller LA, Williams SP, Willson TM, Xu R, Zuercher WJ, et al: Small molecule agonists of the orphan nuclear receptors steroidogenic factor-1 (SF-1, NR5A1) and liver receptor homologue-1 (LRH-1, NR5A2). J Med Chem 54: 2266-2281, 2011.

18. Whitby RJ, Dixon S, Maloney PR, Delerive P, Goodwin BJ, Parks DJ and Willson TM: Identification of small molecule agonists of the orphan nuclear receptors liver receptor homolog-1 and steroidogenic factor-1. J Med Chem 49: 6652-6655, 2006.

19. Corzo CA, Mari Y, Chang MR, Khan T, Kuruvilla D, Nuhant P, Kumar N, West GM, Duckett DR, Roush WR and Griffin PR: Antiproliferation activity of a small molecule repressor of liver receptor homolog 1. Mol Pharmacol 87: 296-304, 2015
20. Benod C, Carlsson J, Uthayaruban R, Hwang P, Irwin JJ, Doak AK, Shoichet BK, Sablin EP and Fletterick RJ: Structure-based discovery of antagonists of nuclear receptor LRH-1. J Biol Chem 288: 19830-19844, 2013.

21. Livak KJ and Schmittgen TD: Analysis of relative gene expression data using real-time quantitative PCR and the $2^{-\Delta \Delta C_{\mathrm{T}}}$ method. Methods 25: 402-408, 2001.

22. Woodfield SE, Shi Y, Patel RH, Jin J, Major A, Sarabia SF, Starosolski Z, Zorman B, Gupta SS, Chen Z, et al: A novel cell line based orthotopic xenograft mouse model that recapitulates human hepatoblastoma. Sci Rep 7: 17751, 2017.

23. Heng JC, Feng B, Han J, Jiang J, Kraus P, Ng JH, Orlov YL, Huss M, Yang L, Lufkin T, et al: The nuclear receptor Nr5a2 can replace Oct 4 in the reprogramming of murine somatic cells to pluripotent cells. Cell Stem Cell 6: 167-174, 2010.

24. Wagner RT, Xu X, Yi F, Merrill BJ and Cooney AJ: Canonical Wnt/beta-catenin regulation of liver receptor homolog-1 mediates pluripotency gene expression. Stem Cells 28: 1794-1804, 2010.

25. Pelengaris S, Khan M and Evan G: c-MYC: More than just a matter of life and death. Nat Rev Cancer 2: 764-776, 2002.

26. Annicotte JS, Chavey C, Servant N, Teyssier J, Bardin A, Licznar A, Badia E, Pujol P, Vignon F, Maudelonde T, et al: The nuclear receptor liver receptor homolog-1 is an estrogen receptor target gene. Oncogene 24: 8167-8175, 2005.

27. Bertolin K, Gossen J, Schoonjans K and Murphy BD: The orphan nuclear receptor $\mathrm{Nr} 5 \mathrm{a} 2$ is essential for luteinization in the female mouse ovary. Endocrinology 155: 1931-1943, 2014.

28. Bayrer JR, Mukkamala S, Sablin EP, Webb P and Fletterick RJ: Silencing LRH-1 in colon cancer cell lines impairs proliferation and alters gene expression programs. Proc Natl Acad Sci USA 112: 2467-2472, 2015.

29. Pietsch T, Fonatsch C, Albrecht S, Maschek H, Wolf HK and von Schweinitz D: Characterization of the continuous cell line HepT1 derived from a human hepatoblastoma. Lab Invest 74: 809-818, 1996.

This work is licensed under a Creative Commons Attribution-NonCommercial-NoDerivatives 4.0 International (CC BY-NC-ND 4.0) License. 